\title{
Gastroesophageal reflux is associated with an increased risk of gastric cardiac polyps: a case-control study of 140 cases
}

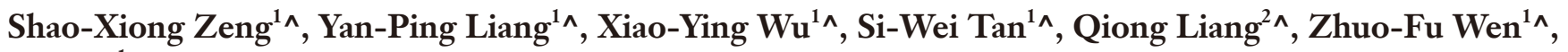 \\ Jin $\mathrm{TaO}^{1 \wedge}$ \\ ${ }^{1}$ Department of Gastroenterology, The Third Affiliated Hospital of Sun Yat-sen University, Guangzhou, China; ${ }^{2}$ Department of Pathology, The \\ Third Affiliated Hospital of Sun Yat-sen University, Guangzhou, China \\ Contributions: (I) Conception and design: SX Zeng, XY Wu, ZF Wen, J Tao; (II) Administrative support: YP Liang, SW Tan; (III) Provision of study \\ materials or patients: SX Zeng, YP Liang, SW Tan, Q Liang, ZF Wen, J Tao; (IV) Collection and assembly of data: SX Zeng, XY Wu; (V) Data \\ analysis and interpretation: SX Zeng, XY Wu; (VI) Manuscript writing: All authors; (VII) Final approval of manuscript: All authors. \\ Correspondence to: Professor Jin Tao, MD, PhD. Department of Gastroenterology, The Third Affiliated Hospital of Sun Yat-sen University, No. 600 \\ Tianhe Road, Guangzhou 510630, China. Email: taojin3@mail.sysu.edu.cn.
}

\begin{abstract}
Backgrounda The pathogenesis of gastric cardiac polyps is not yet clear, and there is little research on their clinical and histopathologic characteristics and correlation with gastroesophageal reflux. Early detection and treatment of premalignant lesions in this area can prevent the development of cancer. We aimed to evaluate the clinical and histopathologic characteristics and risk factors of gastric cardiac polyps to improve the current understanding of the disease.

Methods: Patients diagnosed with gastric cardiac polyps at the Third Affiliated Hospital of Sun Yat-Sen University between January 1, 2010, and December 31, 2019, were sought for the study. The exclusion criteria were missing clinical data, insufficient pathological reports, gastric malignancy, or a previous history of gastroduodenal surgery. Ultimately, 140 patients were included in the case group, while 140 patients diagnosed with chronic superficial gastritis from the same 10-year period were identified randomly and selected as a control group. The exclusion criteria for this group were the same as those for the case group. Patients in both groups were matched in age and gender to ensure comparability between the two groups. We evaluated and compared the demographic and clinical data and endoscopic impressions of each group and analyzed the endoscopic, histologic features of gastric cardiac polyps.
\end{abstract}

Results: Gastroesophageal reflux was significantly associated with a higher risk of gastric cardiac polyps after adjustment for other covariates [adjusted odds ratio $(\mathrm{OR})=2.809$; 95\% confidence interval (CI): 1.178-6.697; $\mathrm{P}=0.020]$. Most gastric polyps were single (97.9\%), sessile (92.8\%), and small polyps with a diameter less than $1 \mathrm{~cm}(88.6 \%)$. Most were located in the gastroesophageal junction region $(65.0 \%)$ with a smooth surface (56.4\%) or surface congestion (30.0\%). Hyperplastic (inflammatory) polyps (88.0\%) were the most common pathological type and comprised gastric-type foveolar epithelium, squamous epithelium, or admixture of the two epithelia, with a minority showing intestinal metaplasia, mild, or moderate epithelial dysplasia.

Conclusions: Gastroesophageal reflux was associated with a significantly higher incidence of gastric cardiac polyps with a 2.8-fold increased risk. Most gastric cardiac polyps were found to be benign lesions and had a favorable prognosis in the clinic despite their malignant potential.

Keywords: Gastric cardiac polyps; gastroesophageal reflux; risk factor; histopathologic features

Submitted Jan 29, 2021. Accepted for publication May 18, 2021.

doi: $10.21037 / \mathrm{apm}-21-260$

View this article at: http://dx.doi.org/10.21037/apm-21-260

\footnotetext{
^ ORCID: Shao-Xiong Zeng, 0000-0002-7358-986X; Yan-Ping Liang, 0000-0001-5291-8479; Xiao-Ying Wu, 0000-0003-2170-0463; Si-Wei Tan, 0000-0002-2414-0011; Qiong Liang, 0000-0001-9567-9121; Zhuo-Fu Wen, 0000-0002-3021-0928; Jin Tao, 0000-0002-4027-0852.
} 


\section{Introduction}

The incidence rate of gastric cardiac adenocarcinoma, sometimes referred to as "adenocarcinoma of the gastroesophageal junction", has significantly increased in the past few decades in both Western countries and Eastern Asia. Compared to non-cardia adenocarcinoma, cardiac adenocarcinoma has a worse prognosis, and the early detection and treatment of premalignant lesions can prevent its progression $(1,2)$. Gastric cardiac polyps are a heterogeneous group of histopathologic entities with malignant potential and are uncommon findings on gastroscopic examination. First described by Bleshman et al., gastric cardiac polyps are believed to represent thickening of the proximal aspect of the sentinel fold and are evolutionary findings in esophagitis (3). Over time, the lesion has been referred to as sentinel polyp, sentinel fold, inflammatory polyp-fold complex, inflammatory fibrous polyp, inflammatory fibroid polyp, prominent esophagogastric fold, eosinophilic granuloma, pseudotumor at the esophagogastric junction, and retrograde gastric mucosal prolapse (3-9). However, these reports have been limited almost exclusively to the radiologic and endoscopic literature, and the clinical and histopathologic characteristics of gastric cardiac polyps have only rarely been illustrated. The first systematic histopathologic analysis of these lesions was in the early 2000s by Abraham et al. (10), who found that hyperplastic polyps were most common in the region of the gastroesophageal junction (67\%), followed by the distal esophagus (30\%), and mid-esophagus (3\%). Most (80\%) were composed of predominantly cardiac-type mucosa, predominantly squamous mucosa $(17 \%)$, or an admixture (3\%), while intestinal metaplasia of the polyp was present in only $7 \%$ and low-grade dysplasia in only $3 \%$. However, that study had a small sample size in only analyzing 30 hyperplastic (inflammatory) polyps (HPs) from 27 patients, and the clinical features of cardiac polyps, especially their endoscopic manifestations, were not elucidated in it or subsequent studies. Therefore, the pathogenesis of gastric cardiac polyps remaining unclear. While a possible link with gastroesophageal reflux disease has been reported in some studies $(3,11-13)$, this has been refuted in others $(14,15)$. Previous studies have often been restricted to individual cases or small series, and there are few case-control studies on the correlation between gastric cardiac polyps and gastroesophageal reflux. Given this, the purpose of this retrospective case-control study was to evaluate the clinical and histopathologic characteristics of gastric cardiac polyps and explore their risk factors. The results may improve our understanding of this disease and provide more clinical references for early and appropriate treatment. We present the following article in accordance with the STROBE reporting checklist (available at http://dx.doi.org/10.21037/ apm-21-260).

\section{Methods}

\section{Study group}

The clinical records of patients diagnosed with gastric cardiac polyps based on gastroscopy between January 1, 2010, and December 31, 2019, were retrospectively collected from the endoscopy center database at the Department of Gastroenterology of the Third Affiliated Hospital of Sun Yat-sen University. The exclusion criteria were missing clinical data, insufficient pathological reports, gastric malignancy, and a previous history of gastroduodenal surgery. Ultimately, a total of 140 patients were included in the case group. Also, patients diagnosed with chronic superficial gastritis were identified randomly and selected as a control group from the same 10 -year period, and the exclusion criteria for this group were the same as for the case group. Both groups were matched according to age and gender to ensure comparability and patient selection, and the main study procedures are listed in the flow chart (Figure 1). Demographic and clinical data, including the age of patients, gender, and clinical symptoms for endoscopy considered pertinent to the study, including epigastric pain, abdominal distention, acid regurgitation, heartburn, belching, nausea and vomiting, anorexia, hematemesis, and black stool, dysphagia, and noncardiac chest pain, were also recorded. The study was conducted in accordance with the Declaration of Helsinki (as revised in 2013). The study was approved by the Institutional Ethics Committee of Third Affiliated Hospital of Sun Yat-sen University as exempted research without registration number and the committee waived the need for informed consent (both written and oral) from participants.

\section{Endoscopic impressions}

Gastrointestinal endoscopy examinations were performed by experienced gastroscopists. Endoscopic findings considered relevant were the presence or absence of hiatal hernia, reflux esophagitis, inflammation of cardia, esophageal and gastric varices, and achalasia. The 


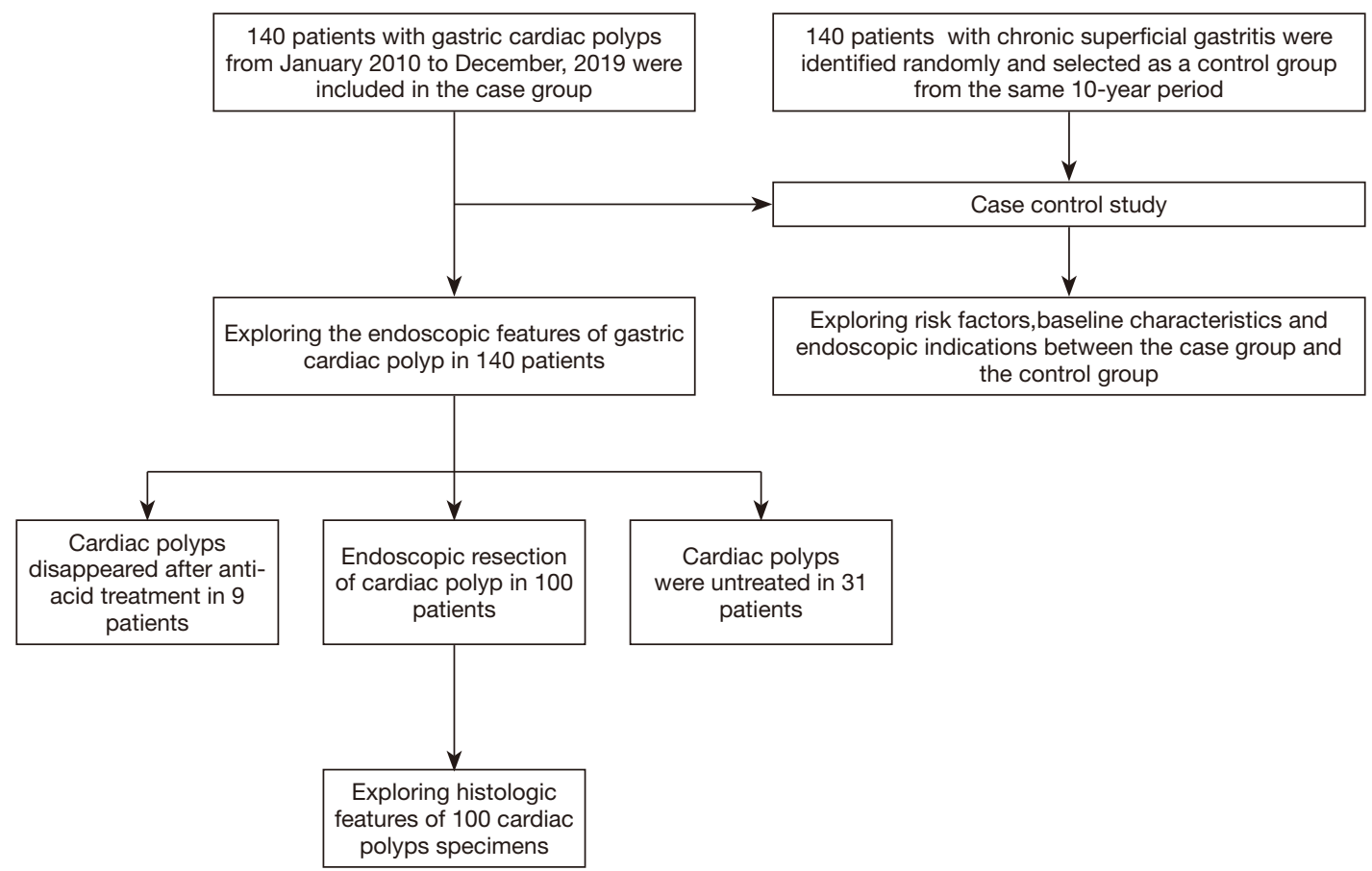

Figure 1 Flow diagram of progress of the two groups through the case control study.

endoscopic features of gastric cardiac polyps in the case group were also collected, including presence of single or multiple polyps, and polyp location, size, morphology, and appearance.

\section{Helicobacter pylori detection}

A specimen from the gastric antral mucosa was obtained during endoscopy to test for Helicobacter pylori infection using a rapid urease test, with a positive test indicating its presence.

\section{Histopathological evaluation}

Experienced pathologists performed histopathological examinations. Routinely processed biopsy or excision specimens fixed in $10 \%$ buffered formalin were stained with hematoxylin and eosin. Pathological sections of the gastric cardiac polyps were evaluated for a variety of morphologic features, including the pathological type, their mucosal lining (gastric-type foveolar epithelium, squamous epithelium, or an admixture of the two epithelia), and the presence or absence of intestinal metaplasia, epithelial dysplasia, intraepithelial neoplasia, and adenocarcinoma.

\section{Statistical analysis}

Statistical analyses were performed by the IBM SPSS Statistic 25.0. Categorical variables were statistically described as the frequency with respective percentages and continuous data as mean \pm standard deviation (SD) or median (interquartile range) according to distribution. $\chi^{2}$ test or Fisher's exact test was used to compare categorical variables, and the Student's $t$-test was used to compare continuous data. A univariate logistic regression analysis was used to evaluate the risk factors of gastric cardiac polyps, and multivariate logistic regression analysis was used to analyze the independent risk factors of gastric cardiac polyps, adjusted for age and sex as covariates. A two-sided $\mathrm{P}$ value $<0.05$ was considered statistically significant.

\section{Results}

\section{Demographics and clinical features}

A total of 140 patients with gastric cardiac polyps as the case group and 140 patients without as the control group was included in the study, and the demographics and clinical features of all patients are summarized in Table 1. There was no significant difference in the general clinical data between 
Table 1 Demographic data, indications for endoscopy in patients with and without gastric cardiac polyps

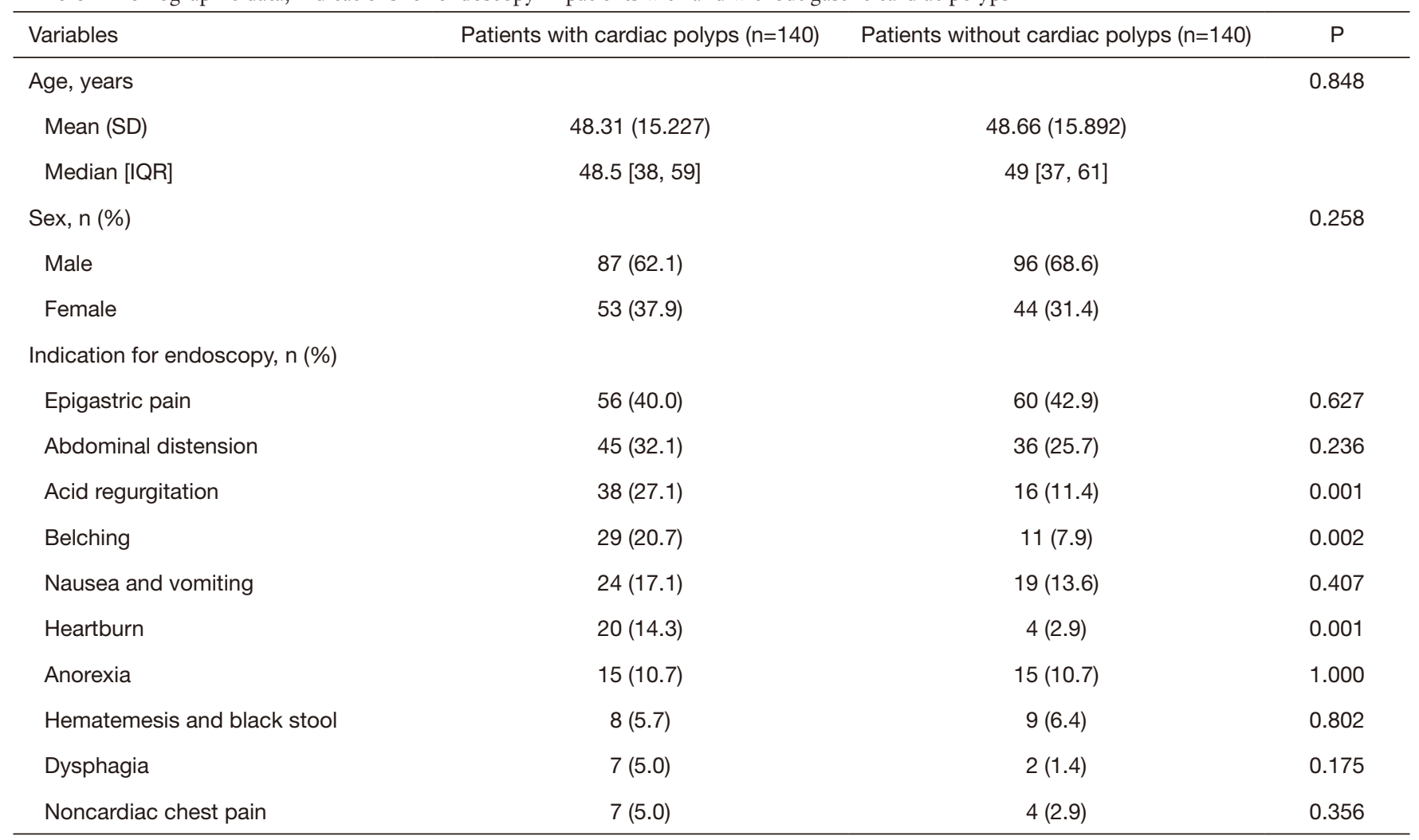

$\mathrm{SD}$, standard deviation; IQR, interquartile range.

the two groups, including age and gender $(\mathrm{P}=0.85$ and $\mathrm{P}=0.26$, respectively), and the age range was similar between the two groups. The mean age of patients in the case group was 48.3 years and consisted of a higher proportion of men than women $(62.1 \%$ vs. $37.9 \%)$, revealing that patients with gastric cardiac polyps were predominantly middle-aged males.

The indications for endoscopy were recorded in the two groups and there were significant differences in the incidence of acid regurgitation, heartburn, and belching, being significantly higher in the case group $(27.1 \%$ vs. $11.4 \%, \mathrm{P}=0.001 ; 14.3 \%$ vs. $2.9 \%, \mathrm{P}=0.001$ and $20.7 \%$ vs. $7.9 \%, \mathrm{P}=0.002$, respectively). The most common indication for endoscopy in patients in the case group was epigastric pain $(40.0 \%)$. In comparison, other indications were abdominal distention (32.1\%), nausea and vomiting (17.1\%), anorexia (10.7\%), hematemesis and black stool (5.7\%), dysphagia (5.0\%) and noncardiac chest pain (5.0\%), which were not statistically significant compared with the patients without gastric cardiac polyps.
Univariate and multivariate logistic regression analysis of risk factors for gastric cardiac polyps

Case-control comparisons of risk factors for gastric cardiac polyps by univariate logistic regression are summarized in Table 2. Within the case group, gastroesophageal reflux was significantly associated with a higher risk of gastric cardiac polyps [odds ratio $(\mathrm{OR})=2.750$; 95\% CI: 1.168 6.475; $\mathrm{P}<0.05]$, whereas Helicobacter pylori infection, which is known to be associated with gastric polyps, was not a risk factor $(\mathrm{OR}=0.764 ; 95 \% \mathrm{CI}: 0.371-1.573 ; \mathrm{P}=0.464)$. Similarly, factors including hiatal hernia, inflammation of the cardia, and esophageal and gastric varices showed no significant correlation between the case and control group. Table 3 shows that gastroesophageal reflux was found to be independently and significantly associated with patients with gastric cardiac polyps by multivariate logistic regression compared with control subjects with an adjusted OR of 2.809 (95\% CI: 1.178-6.697; $\mathrm{P}=0.020$ ), after adjustment for age, gender, and risk factors including Helicobacter pylori 
Table 2 Univariate logistic regression analysis of risk factors for gastric cardiac polyps

\begin{tabular}{lccc}
\hline Variables & $\begin{array}{c}\text { Patients with cardiac polyps } \\
(\mathrm{n}=140), \mathrm{n}(\%)\end{array}$ & $\begin{array}{c}\text { Patients without cardiac polyps } \\
(\mathrm{n}=140), \mathrm{n}(\%)\end{array}$ & OR (95\% Cl) \\
\hline Gastroesophageal reflux & $20(14.3)$ & $8(5.7)$ & $2.750(1.168-6.475)$ \\
Hiatal hernia & $1(0.7)$ & $2(1.4)$ & $0.496(0.044-5.538)$ \\
Inflammation of cardia & $4(2.9)$ & $9(6.4)$ & $0.428(0.129-1.424)$ \\
$\begin{array}{l}\text { Esophageal and gastric } \\
\text { varices }\end{array}$ & $11(7.9)$ & $7(5.0)$ & $1.620(0.609-4.309)$ \\
$\begin{array}{l}\text { Helicobacter pylori } \\
\text { infection }\end{array}$ & $15(10.7)$ & $19(13.6)$ & $0.764(0.371-1.573)$ \\
\hline
\end{tabular}

OR, odds ratio; $\mathrm{Cl}$, confidence interval.

Table 3 Multivariate logistic regression analysis of independent predictors of gastric cardiac polyps

\begin{tabular}{lccc}
\hline Variables & Adjusted odds ratio & $95 \% \mathrm{Cl}$ & P value \\
\hline Gastroesophageal reflux & 2.809 & $1.178-6.697$ & 0.020 \\
Hiatal hernia & 0.575 & $0.050-6.551$ & 0.656 \\
Inflammation of cardia & 0.396 & $0.115-1.364$ & 0.142 \\
Esophageal and gastric varices & 1.795 & $0.651-4.950$ & 0.258 \\
Helicobacter pylori infection & 0.859 & $0.409-1.804$ & 0.687 \\
Age & 0.998 & $0.982-1.013$ & 0.778 \\
Sex & 0.689 & $0.415-1.145$ & 0.151 \\
\hline
\end{tabular}

$\mathrm{Cl}$, confidence interval.

infection, hiatal hernia, inflammation of the cardia, and esophageal and gastric varices.

\section{Endoscopic impressions of gastric cardiac polyps}

Figure 2 show different endoscopic views of gastric cardiac polyps, and Table 4 outlines their main endoscopic features. Most polyps were found at the gastroesophageal junction region (91 patients, $65.0 \%$ ), followed by the region distal to the gastroesophageal junction in (43 patients, 30.7\%), and rarely, the region proximal to the gastroesophageal junction (6 patients, $4.3 \%$ ). Most polyps were single (137 patients $97.9 \%$ ), while multiple in only three patients (2.1\%), two of whom had two polyps and one who had three polyps. The most common morphology type was sessile polyps in 130 patients (92.8\%), followed by a small proportion of subpedunculated polyps in five patients (3.6\%) and pedunculated polyps in a further five patients $(3.6 \%)$. Most polyps were small $(33.6 \%$ measured $\leq 0.5 \mathrm{~cm}$ and $55.0 \%$ measured $0.5-1 \mathrm{~cm}$ ), with an average size of $0.7 \mathrm{~cm}$, ranging from 0.1 to $2 \mathrm{~cm}$. The most common appearance of polyps was a smooth surface (56.4\%), followed by surface congestion $(30.0 \%)$, while less common were a rough surface $(5.7 \%)$, erosive surface $(4.3 \%)$, and surface edema and congestion (3.6\%).

\section{Histopathologic features}

Figure 3 show the salient histopathologic features of gastric cardiac polyps, and Table 5 summarizes these in the study cases. Tissue pathology types of gastric cardiac polyps included HPs $(88.0 \%)$, adenomatous polyps $(5.0 \%)$, fundic gland polyps $(2.0 \%)$, squamous papillomas $(2.0 \%)$, hamartomatous polyps (2.0\%), and xanthelasma (1.0\%). Further analysis of the histopathological features of HPs revealed that the most common mucosa was gastrictype foveolar epithelium (72.7\%), followed by squamous epithelium (9.1\%), and an admixture of the two epithelia $(18.2 \%)$. Intestinal metaplasia was detected in four of the HPs (4.5\%), while mild epithelial dysplasia was seen in 

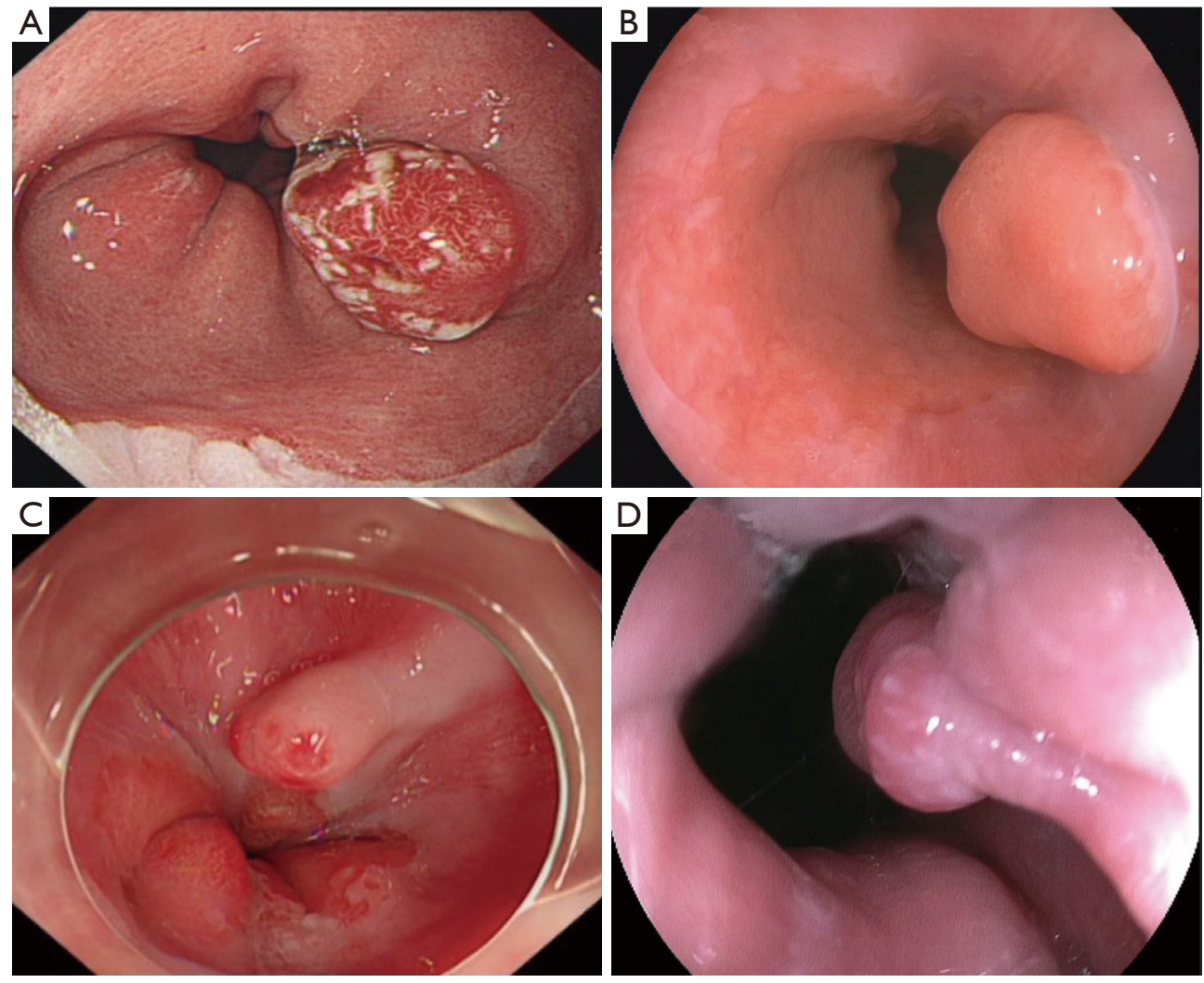

Figure 2 Different endoscopic impressions of gastric cardiac polyps. (A) A single pedunculated gastric cardiac adenomatous polyp located distal to the gastroesophageal junction with surface congestion; (B) a single sessile gastric cardiac polyp located in the gastroesophageal junction and with a smooth surface; (C) a single subpedunculated gastric cardiac polyp located in the gastroesophageal junction and with a smooth surface; (D) a single pedunculated gastric cardiac polyp located in the gastroesophageal junction with surface congestion.

five $(5.7 \%)$, and moderate epithelial dysplasia was seen in two $(2.3 \%)$. No cases of intraepithelial neoplasia or adenocarcinoma were found in patients in the case group.

\section{Discussion}

Gastric cardiac polyps comprise a heterogeneous group of histopathologic entities, including squamous papilloma, leiomyoma, Barrett esophagus (BE)-associated polypoid dysplasia, polypoid carcinoma, fundic gland polyps, and HPs $(16,17)$. As they are not commonly encountered in the clinical setting, gastric cardiac polyps' etiology and biological characteristics have attracted little attention and remain fully elucidated. In this retrospective casecontrol study, we investigated the clinical and pathologic characteristics of gastric cardiac polyps by comparing a case and control group and found that compared with the control group, the case group were predominantly middle- aged males with a significantly higher incidence of acid regurgitation, heartburn, and belching. Gastroesophageal reflux was significantly associated with a higher risk of gastric cardiac polyp incidence after adjustment for other covariates (adjusted OR $=2.809$; 95\% CI: 1.178-6.697; $\mathrm{P}=0.020$ ), while Heliobacter pylori infection was not (adjusted OR $=0.859 ; 95 \%$ CI: $0.409-1.804 ; \mathrm{P}=0.687$ ). Most polyps were single, sessile, and small, with a diameter less than $1 \mathrm{~cm}$, were located in the gastroesophageal junction region and had a smooth surface or surface congestion. HPs were the most common pathological type and comprised gastric-type foveolar epithelium, squamous epithelium, or admixture of the two epithelia, with a minority composed of intestinal metaplasia and mild or moderate epithelial dysplasia.

While their etiology and pathogenesis remain ambiguous, our retrospective case-control study revealed that gastroesophageal reflux was associated with a significantly 
Table 4 Endoscopic features of gastric cardiac polyps

\begin{tabular}{lc}
\hline Endoscopic features & No. of patients $(\%)$ \\
\hline Polyp location & \\
Proximal to the gastroesophageal junction & $6(4.3)$ \\
Gastroesophageal junction region & $91(65.0)$ \\
Distal to the gastroesophageal junction & $43(30.7)$ \\
Number of gastric cardiac polyps & \\
Single & $137(97.9)$ \\
Multiple & $3(2.1)$ \\
Polyp size & \\
$\leq 0.5$ cm & $47(33.6)$ \\
$0.5-1$ cm & $77(55.0)$ \\
1-1.5 cm & $15(10.7)$ \\
1.5-2 cm & $1(0.7)$ \\
Polyp morphology & \\
Sessile & $130(92.9)$ \\
Subpedunculated & $5(3.6)$ \\
Pedunculated & $5(3.6)$ \\
Solyp appearance & \\
Surface edema and congestion & \\
\hline
\end{tabular}

higher incidence of gastric cardiac polyps, with a 2.8 -fold increased risk. Further, Helicobacter pylori infection, known to be associated with gastric polyps (18), was not a risk factor of gastric cardiac polyps, supporting the results of previous case reports. The current prevailing theory is that gastric cardiac polyps are frequently associated with severe esophagitis and/or underlying anatomic abnormalities of the esophagus and likely represent a hyper-regenerative and metaplastic response to chronic mucosa injury $(10,16)$, the most common proposed etiology for which is gastroesophageal reflux disease $(3,11-13)$. In a clinical and pathologic study of 46 cases with gastroesophageal junction hyperplastic polyps (16), Long et al. found that up to onethird of hyperplastic polyps in this region represented a hyper-regenerative and metaplastic response to chronic injury caused by gastroesophageal reflux disease. Acid reflux impairs esophageal barrier function through direct chemical injury (acid and enzymes), and subsequent tissue damage leads to esophageal mucosal damage and inflammation (19). There is also evidence that treatment of gastroesophageal reflux is an effective therapy for gastric cardiac polyps. One study reported an inflammatory gastroesophageal polyp resolved following anti-reflux surgery (11), and in our study, gastric cardiac polyps disappeared after anti-acid therapy in nine patients without endoscopic resection. The use of the proton pump inhibitor lansoprazole over 5 months was effective for treating inflammatory esophagogastric polyps in children, with optimal duration of more than 7 months for complete resolution of the polyp (9). Hirasaki et al. reported that following administration of a protonpump inhibitor for 3 months, endoscopy showed resolution of $1 \mathrm{~cm}$ gastric cardiac polyps in a 42 -year-old man who visited the hospital for further evaluation of heartburn (20). However, whether anti-acid therapy should be considered first-line treatment of patients with gastric cardiac polyps is challenged by some, including Melton and Genta, who showed that there was no significant association with gastroesophageal reflux disease, esophagitis, Barrett esophagus, reactive gastropathy, or gastritis, with or without Heliobacter pylori (21).

In addition to acid-reflux, other forms of gastroesophageal mucosal injury, including severe vomiting, Crohn's disease, medication-associated esophagitis, infectious esophagitis, anatomic abnormalities, and photodynamic therapy are likely to play a role in the formation of gastric cardiac polyps in smaller subsets of patients $(10,22,23)$. However, factors including hiatal hernia, inflammation of the cardia, and esophageal and gastric varices, which have been associated with gastric cardiac polyps, did not significantly increase their risk control group in our study.

Pathological results in our study confirm that gastric cardiac polyps are a heterogeneous group of histopathologic entities, including HPs, adenomatous polyps, fundic gland polyps, squamous papillomas, hamartomatous polyps, and xanthelasma. The results demonstrated that most were HPs, which are an inflammatory proliferation of gastric foveolar cells. Foveolar hyperplasia and inflammatory edema are essential for the formation of hyperplastic polyps with intraluminal projections (24), and when the inflammatory infiltrates are prominent, they may be referred to as inflammatory polyps (25). Further analysis of the histopathological features of HPs revealed that the 
A
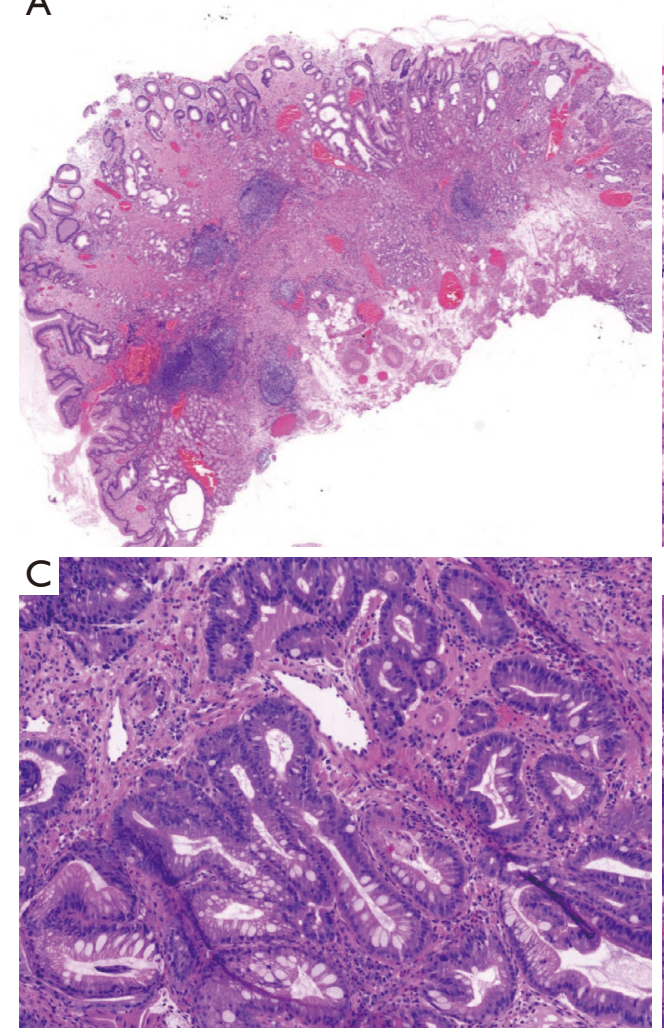

B
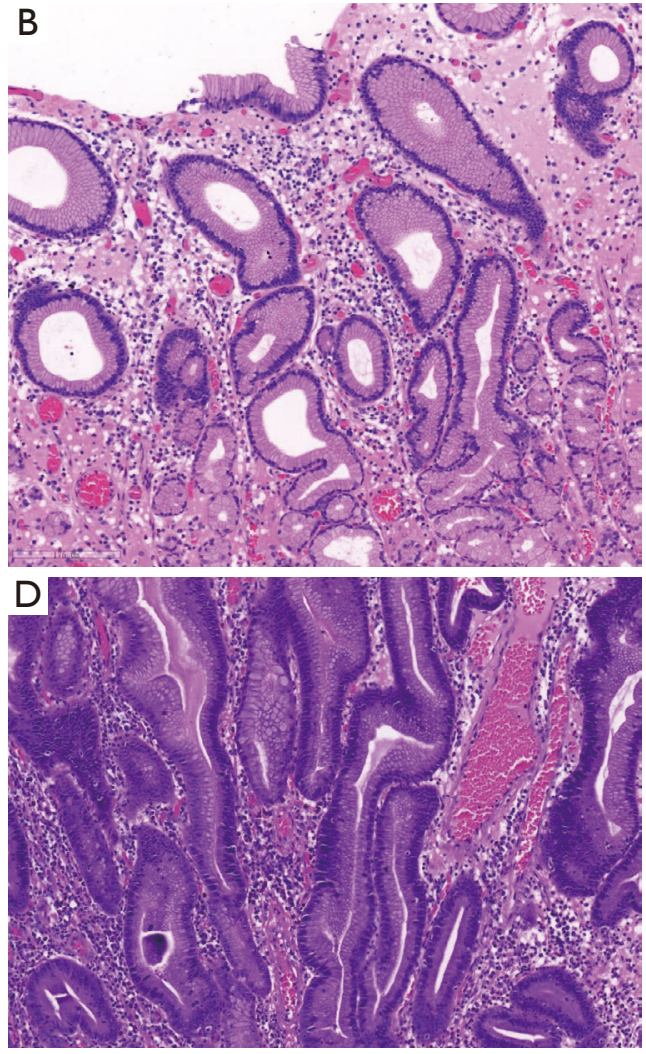

Figure 3 Histopathologic features of gastric cardiac polyps. (A) Hematoxylin-eosin staining revealed a gastric cardiac polyp was comprised of gastric-type foveolar epithelium mucosa, abundant gland hyperplasia in the lamina propria with cystic dilatation of some glands, and notable interstitial hyperemia and edema with infiltration by lymphocytes and plasma cells (magnification: $\times 100$ ), which is seen more clearly at higher magnification (×200) in (B). (C) Another gastric cardiac polyp showed local gland hyperplasia with intestinal metaplasia microscopically (magnification: $\times 200$ ). (D) Microscopically, another gastric cardiac polyp showed that glandular epithelium cells were lowgrade dysplasia and the nucleus were elongated, deeply stained, and crowded, indicating adenomatous polyps (magnification: $\times 200$ ).

most common mucosa involved was gastric-type foveolar epithelium (72.7\%), with squamous epithelium involved in $9.1 \%$ and admixture of the two epithelia in $18.2 \%$. We also found that among the 88 cases of HPs, four cases (4.5\%) had intestinal metaplasia, five cases $(5.7 \%)$ had mild epithelial dysplasia, and two cases $(2.3 \%)$ had moderate epithelial dysplasia, which indicates a risk for neoplastic progression. Previous studies supported this view, including Laxen, who suggested that hyperplastic polyps and foveolar hyperplasia in patients with atrophic corpus gastritis were associated with an increased risk of gastric cancer (26), and Zea-Iriarte $e t$ al., who found that hyperplastic polyps have malignant potential (27). Genetic analyses have revealed that simultaneous large gastric hyperplastic polyps have a clonal origin and may account for neoplastic tumors (28), and Nogueira et al. found that replication error phenotype occurs in hyperplastic polyps linked to the process of malignant transformation (29). These studies suggest that although the risk is considerably lower than that associated with adenomas, hyperplastic polyps can develop into carcinoma. Thus, biopsies and histopathological examination are essential for diagnosing hyperplastic polyps for the early detection and treatment of malignant lesions.

Most gastric cardiac polyps are benign and have a favorable prognosis in the clinic, despite retaining malignant potential, and in our study, no intraepithelial neoplasia or adenocarcinoma was found in patients in the case group. Abraham et al. conducted a clinicopathologic study of 30 hyperplastic polyps of the esophagus and esophagogastric junction, of which 10 were from the mid or distal esophagus and 20 were from the esophagogastric junction and found no association with concurrent, previous, or subsequent 
Table 5 Pathologic features of gastric cardiac polyps

\begin{tabular}{|c|c|}
\hline Pathologic findings & No. of patients (\%) \\
\hline Hyperplastic (inflammatory) polyps & $88(88.0)$ \\
\hline Xanthelasma & $1(1.0)$ \\
\hline Gastric fundic gland polyps & $2(2.0)$ \\
\hline Hamartomatous polyps & $2(2.0)$ \\
\hline Adenomatous polyps & $5(5.0)$ \\
\hline Adenocarcinoma & $0(0)$ \\
\hline \multicolumn{2}{|l|}{ Mucosal lining of hyperplastic (inflammatory) polyps } \\
\hline An admixture of the two epithelia & $16(18.2)$ \\
\hline Intestinal metaplasia within hyperplastic (inflammatory) polyps & $4(4.5)$ \\
\hline \multicolumn{2}{|l|}{ Epithelial dysplasia within hyperplastic (inflammatory) polyps } \\
\hline Normal & $81(92.0)$ \\
\hline Mild & $5(5.7)$ \\
\hline Moderate & $2(2.3)$ \\
\hline Severe & $0(0)$ \\
\hline Intraepithelial neoplasia & $0(0)$ \\
\hline
\end{tabular}

esophageal carcinoma (10). Also, follow-up upper endoscopy included esophageal biopsy performed in seven patients showed no subsequent hyperplastic polyps. Long et al. conducted a clinical and pathologic study of 46 cases with gastroesophageal junction hyperplastic polyps (16). They found that while several patients showed persistent gastritis, only one had recurrent hyperplastic polyps, and none developed dysplasia or carcinoma during follow-up upper endoscopy. Based on these studies, we conclude that gastric cardiac polyps have an excellent prognosis with a very low recurrence rate. However, further studies with large-sample, multicenter data to investigate prognosis and follow-up are required to verify the present results.

The present retrospective case-control study is meaningful, as it included a larger number of patients than other retrospective studies. Also, we identified the clinical and pathologic characteristics of gastric cardiac polyps and assessed their potential risk factors, with the key findings showing gastroesophageal reflux increased their risk 2.8-fold. Nevertheless, there are some limitations in this research that warrant discussion. First, this was a single-center, retrospective study with a limited number of subjects, which may affect the strength of the conclusions, and a multicenter study with large sample size is required to verify the results. Second, although gastric cardiac polyps disappeared after anti-acid therapy in nine patients without endoscopic resection, we have not been able to elucidate the optimal treatment time for this treatment because the patients failed to revisit the hospital regularly. Third, as we did not perform long-term follow-up on patients in the case group, we could not elucidate the long-term prognosis of patients with gastric cardiac polyps regarding the number and frequency of relapses.

\section{Conclusions}

In summary, this retrospective study confirmed that patients with gastric cardiac polyps are predominantly middle- 
aged males with a significantly high incidence of acid regurgitation, heartburn, and belching. Gastroesophageal reflux was associated with a significantly higher incidence of gastric cardiac polyps with a 2.8 -fold increased risk, and anti-acid therapy should be considered as a first-line treatment. Most gastric cardiac polyps were single, sessile, and small polyps, located in the gastroesophageal junction region with a smooth surface or surface congestion. Importantly, while having malignant potential, most gastric cardiac polyps are benign lesions and have a favorable prognosis.

\section{Acknowledgments}

Funding: This work was supported by the National Natural Science Foundation for Young Scientists of China (81800458), the Natural Science Foundation of Guangdong Province (2017A030310188), the Science and Technology Planning Projects of Guangzhou City (201804010026), and the Science and Technology Planning Project of Guangdong Province (2016A020216014).

\section{Footnote}

Reporting Checklist: The authors have completed the STROBE reporting checklist. Available at http://dx.doi. org/10.21037/apm-21-260

Data Sharing Statement: Available at http://dx.doi. org/10.21037/apm-21-260

Conflicts of Interest: All authors have completed the ICMJE uniform disclosure form (available at http://dx.doi. org/10.21037/apm-21-260). The authors have no conflicts of interest to declare.

Ethical Statement: The authors are accountable for all aspects of the work in ensuring that questions related to the accuracy or integrity of any part of the work are appropriately investigated and resolved. All procedures performed in this study were following the Helsinki Declaration (as revised in 2013). The study was approved by the Institutional Ethics Committee of Third Affiliated Hospital of Sun Yat-Sen University as exempted research without registration number and the committee waived the need for informed consent (both written and oral) from participants.
Open Access Statement: This is an Open Access article distributed in accordance with the Creative Commons Attribution-NonCommercial-NoDerivs 4.0 International License (CC BY-NC-ND 4.0), which permits the noncommercial replication and distribution of the article with the strict proviso that no changes or edits are made and the original work is properly cited (including links to both the formal publication through the relevant DOI and the license). See: https://creativecommons.org/licenses/by-nc-nd/4.0/.

\section{References}

1. Corley DA, Kubo A. Influence of Site Classification on Cancer Incidence Rates: An Analysis of Gastric Cardia Carcinomas. J Natl Cancer Inst 2004;96:1383-7.

2. Yang H, Zhang C, Fang S, et al. UCH-LI acts as a novel prognostic biomarker in gastric cardiac adenocarcinoma. Int J Clin Exp Pathol 2015;8:13957-67.

3. Bleshman MH, Banner MP, Johnson RC, et al. The inflammatory esophagogastric polyp and fold. Radiology 1978;128:589-93

4. Jones TB, Heller RM, Kirchner SG, et al. Inflammatory esophagogastric polyp in children. AJR Am J Roentgenol 1979;133:314-6.

5. Ostrovsky P, Keller RJ. Inflammatory esophagogastric polyp: roentgen features. Mt Sinai J Med 1981;48:137-9.

6. Mohandas KM, Santhi Swaroop V, Krishnamurthy S, et al. Sentinel Polyp and Fold: Resolution Following Drug Therapy. Endoscopy 1992;24:293-4.

7. Bishop PR, Nowicki MJ, Subramony C, et al. The inflammatory polyp-fold complex in children. J Clin Gastroenterol 2002;34:229-32.

8. Sathiyasekeran M, Shivbalan S. Nocturnal cough and esophagogastric polyp: causal or casual association? Indian Pediatr 2007;44:613-5.

9. Choi KE, Kim MJ, Lee JH, et al. Effects of Proton Pump Inhibitors on Pediatric Inflammatory Esophagogastric Polyps. Digestion 2012;85:179-84.

10. Abraham SC, Singh VK, Yardley JH, et al. Hyperplastic polyps of the esophagus and esophagogastric junction: histologic and clinicopathologic findings. Am J Surg Pathol 2001;25:1180-7.

11. Zitsman JL, Schullinger JN, Berdon WE. Inflammatory esophagogastric polyps: resolution following antireflux surgery. J Pediatr Surg 1988;23:1016-7.

12. Rabin MS, Bremner CG, Botha JR. The reflux gastroesophageal polyp. Am J Gastroenterol 
1980;73:451-2.

13. Styles RA, Gibb SP, Tarshis A, et al. Esophagogastric polyps: radiographic and endoscopic findings. Radiology 1985;154:307-11.

14. Stafford EM, Imai WK. Gastroesophageal polyp diagnosed in an adolescent presenting with epigastric pain. J Adolesc Health Care 1987;8:441-4.

15. Van der Veer LD, Kramer K, Relkin R, et al. The esophagogastric polyp-fold complex. Am J Gastroenterol 1984;79:918-20

16. Long KB, Odze RD. Gastroesophageal junction hyperplastic (inflammatory) polyps: a clinical and pathologic study of 46 cases. Am J Surg Pathol 2011;35:1038-44.

17. Carmack SW, Genta RM, Schuler CM, et al. The current spectrum of gastric polyps: a 1-year national study of over 120,000 patients. Am J Gastroenterol 2009;104:1524-32.

18. Nam SY, Park BJ, Ryu KH, et al. Effect of Helicobacter pylori infection and its eradication on the fate of gastric polyps. Eur J Gastroenterol Hepatol 2016;28:449-54.

19. Fang $\mathrm{Y}$, Chen $\mathrm{H}, \mathrm{Hu} \mathrm{Y}$, et al. Gastroesophageal reflux activates the NF-kappaB pathway and impairs esophageal barrier function in mice. Am J Physiol Gastrointest Liver Physiol 2013;305:G58-65.

20. Hirasaki S, Koide N, Suzuki S, et al. Resolution of an inflammatory esophagogastric polyp. Intern Med 2011;50:2047-8.

21. Melton SD, Genta RM. Gastric cardiac polyps: a

Cite this article as: Zeng SX, Liang YP, Wu XY, Tan SW, Liang Q, Wen ZF, Tao J. Gastroesophageal reflux is associated with an increased risk of gastric cardiac polyps: a case-control study of 140 cases. Ann Palliat Med 2021;10(7):7173-7183. doi: 10.21037/apm-21-260 clinicopathologic study of 330 cases. Am J Surg Pathol 2010;34:1792-7.

22. Murney RG Jr, Huston JD. Endoscopic evaluation of the esophagogastric polyp and fold. Gastrointest Endosc 1983;29:294-6.

23. Cockey BM, Jones B, Bayless TM, et al. Filiform polyps of the esophagus with inflammatory bowel disease. AJR Am J Roentgenol 1985;144:1207-8.

24. Voutilainen M, Juhola M, Farkkila M, et al. Foveolar hyperplasia at the gastric cardia: prevalence and associations. J Clin Pathol 2002;55:352-4.

25. Shaib YH, Rugge M, Graham DY, et al. Management of gastric polyps: an endoscopy-based approach. Clin Gastroenterol Hepatol 2013;11:1374-84.

26. Laxén F. Gastric carcinoma and pernicious anaemia in long-term endoscopic follow-up of subjects with gastric polyps. Scand J Gastroenterol 1984;19:535-40.

27. Zea-Iriarte WL, Sekine I, Itsuno M, et al. Carcinoma in gastric hyperplastic polyps. A phenotypic study. Dig Dis Sci 1996;41:377-86.

28. Dijkhuizen SM, Entius MM, Clement MJ, et al. Multiple hyperplastic polyps in the stomach: evidence for clonality and neoplastic potential. Gastroenterology 1997;112:561-6.

29. Nogueira AM, Carneiro F, Seruca R, et al. Microsatellite instability in hyperplastic and adenomatous polyps of the stomach. Cancer 1999;86:1649-56. 